\title{
Seed morphology and anatomy of Rubus geoides Sm.
}

Melissa Fredes ${ }^{1}$, Carlos Muñoz ${ }^{1}$, Loreto Prat ${ }^{1}$, Francisco Torres ${ }^{2}$, Pedro Sāez ${ }^{2}$,

Leonardo Bustamante ${ }^{2}$, Leonardo Paiva ${ }^{2}$, and Ricardo Pertuze ${ }^{-1 *}$

\section{ABSTRACT}

Rubus geoides $\mathrm{Sm}$. is a wild raspberry native in Patagonia. Its domestication can broaden the genetic base of the cultivated raspberry, prevent over exploitation of wild populations, and diversify fruit production in areas where few fruit species can be cultivated, like the Chilean Patagonia. One important step in the domestication of plant species is the unveiling of the reproductive biology of the species, particularly seed germination. The goal of this work was to study seed morphology and anatomy of $R$. geoides in order to identify possible factors that may affect germination and species identification based on seed morphology, since seed shape, surface sculpturing and raphe characteristics are discriminating factors for species identification within Rubus. Morphoanatomical studies were performed using both scanning electron microscopy (SEM) and light microscopy. Rubus geoides seeds turned out to be similar to those of $R$. idaeus. Seeds were pale brown, with a semi globular shape, sharpened at the apical region and oval toward the opposite end. Seed size was variable, showing an average $1.9 \mathrm{~mm}$ width, $2.6 \mathrm{~mm}$ length, and $1.3 \mathrm{~mm}$ thickness. Small rounded depressions and ridges sculptured seed surface. The endocarp was hard and rough, and consist of several layers of sclerenchymatous lignified cells with $139 \mu \mathrm{m}$ averaged thickness, which suggest that to enhanced germination seed may require its weakening or eventual elimination, as is done in other Rubus species. The embryo varied with seed size between 1.6 and $2.0 \mathrm{~mm}$. Energy Dispersive X-Ray Spectroscopy allowed for the identification of the endosperm cells.

Key words: Raphe, SEM, wild raspberry.

${ }^{1}$ Universidad de Chile, Facultad de Ciencias Agronómicas, Avda. Santa Rosa 11315, Santiago, Chile.

*Corresponding author (rpertuze@uchile.cl).

${ }^{2}$ Policía de Investigaciones de Chile, Laboratorio de Criminalística,

Sección Microanálisis, Carlos Silva Vildósola 9783, Santiago, Chile.

Received: 26 January 2016.

Accepted: 29 March 2016.

doi:10.4067/S0718-58392016000300018

\section{INTRODUCTION}

The Chilean wild raspberry (Rubus geoides Sm.), known in Chile as Magellan strawberry or Miñemiñe, is a plant native to Chilean and Argentinian Patagonia. Its geographical distribution in Chile occurs between $35^{\circ}$ and $55^{\circ} \mathrm{S}$ lat, but is more abundant in the Magellan Region. It grows mainly in forest clearings or in land with direct incidence of sunlight, from sea level to the altitudinal limit of vegetation (Arena and Vater, 2005).

The fruit is red and fleshy, smaller than that of the cultivated raspberry, and is commonly collected from the wild to be eaten fresh or processed as jams or jellies (Arena and Vater, 2005). As in all species of the genus Rubus, the fruit is a drupecetum, an aggregate fruit that consist of many drupelets (pyrene) attached to a receptacle. Each druplet is a small drupe formed by a thin exocarp, a fleshy mesocarp and a sclerenchymatous endocarp that surrounds the seed (Tomlik-Wyremblewska et al., 2010).

The genus belongs to the Rosaceae family and $R$. geoides is one of the 750 species of the genus, within the subgenus Comaropsis (Thompson, 1995). The genus Rubus also includes some wellknown cultivated species such as the red raspberry (R. idaeus) and the wild blackberry (R. ulmifolius).

Global demand for fruits with functional properties (antiinflammatory, anti-cancer, or with antioxidant activity that prevent certain diseases) is increasing. These functional properties generally come from high levels of ascorbic acid (vitamin C) and phenolics, such as flavonoids (anthocyanins), polyphenols (tannins) and other compounds (Jiménez-García et al., 2013). For these reasons, modern breeding objectives currently not only consider high fruit yield and quality, good plant adaptation, and resistance to biotic (pests and diseases) and abiotic stresses (cold, salinity, wind, etc.), but also an increment in the functional properties of fruits and vegetables (Vauzour et al., 2010). In most cases, breeding for functional traits requires the broadening of the genetic base of the breeding populations, which can be done by incorporating germplasm from wild species (Jiménez-García et al., 2013). Recent data indicate that $R$. geoides has 39 phenolic compounds, including flavonol glycosides and tannins, in higher concentrations than in $R$. idaeus and that its fruit extracts may induce the activation of intracellular protection mechanisms against oxidative and dicarbonyl-induced stresses (Jiménez-Aspee et al., 2016).

The domestication of $R$. geoides open opportunities to use this species to broaden the genetic base of the cultivated raspberry, to prevent the over exploitation of the wild populations because of 
fruit gathering, and to diversify fruit production in the few areas of Patagonia where fruit species are cultivated under very restrictive weather conditions.

For plant domestication, it is essential to understand the reproductive biology of the species to be domesticated. These include the type of pollination (autogamous $v s$. allogamous), need for pollinators, fruit growth and ripening pattern, and the requirements for seed germination (Cancino-Escalante et al., 2012).

In Rubus, seed generally exhibit low germination rates, because most species have double dormancy: embryo dormancy induced by specific germination inhibitors within the embryo; and the dormancy imposed by the structure surrounding the embryo (Bewley et al., 2013), which is the fruit endocarp that enclose the seed and prevent water imbibition and oxygen exchange with the environment (Zasada and Tappeiner, 2008). The different species of Rubus exhibit great variability in the characteristics of the endocarp. These differences have been thoroughly described by Wada and Reed (2011), but their study did not include $R$. geoides. Also, since shape, surface sculpturing and characteristic of seed raphe are discriminating factors for species identification within Rubus, description of these characteristics may be useful for species identification based on seed morphology (Satomi and Naruhashi, 1971). Therefore, the goal of this work was to provide information about morphology and anatomy of $R$. geoides seed, in order to identify possible factors that may affect germination and species identification based on seed morphology, since seed shape, surface sculpturing and raphe characteristics are discriminating factors for species identification within Rubus.

\section{MATERIALS AND METHODS}

Rubus geoides germplasm was obtained from the Germplasm Bank of the Facultad de Ciencias Agronómicas of the Universidad de Chile. The Bank seeds came from fully mature fruits, collected in areas near Punta Arenas, Magallanes Region (53 $23^{\prime}$ S; $\left.71^{\circ} 00^{\prime} \mathrm{W}\right)$, Chile. To extract the seed, fruit were put in a blender with abundant tap water and mixed for $2 \mathrm{~min}$. Seed were allowed to settle at the bottom of the blender jar for several times. Finally, seed was collected in a strainer, spread onto paper towels and allowed to dry for 1-2 d at room temperature. Seeds were stored in paper bags at room temperature, until their use.

Morphoanatomical studies were performed at the Laboratorio de Anatomía Vegetal, Facultad de Ciencias Agronómicas, Universidad de Chile and at the Laboratorio de Criminalística de la Policía de Investigaciones de Chile. Scanning Electron Microscope Images were obtained with a Quanta Environmental (SEM, Quanta 3D 200i, FEI, Hillsboro, Oregon, USA), equipped with a Focused Ion Beam and Energy Dispersive X-Ray Detector (FIB-EDX), of the Laboratorio de Criminalística. Seed samples in their natural state with no shading treatment, were mounted on aluminum stubs on a double-sided adhesive carbon tape, and placed in different positions to facilitate their observation. SEM images of 25 seeds were used to determine their dimensions (length $\times$ width $\times$ height), endocarp surface, micropyle, and seed raphe and back. Also fractured seeds were used to study seed anatomy. To complement the anatomical description, elemental chemical analysis of seed tissue was made using an X-ray energy dispersive spectroscope, equipped with a detector (Apollo XL, EDAX, Mahwah, New Jersey, USA) and coupled to Genesis software (version 6.37).

Microscopic observations were also made using a light stereo microscope (SZ51, Olympus Corporation, Tokyo, Japan) equipped with a MEM1300R USB digital microscope camera. Images were processed using the WINJOE software (Hangzhou Future Optics Sci. \& Tech. Co., Hangzhou China).

\section{RESULTS AND DISCUSSION}

Color of $R$. geoides seeds was pale brown. Regarding its morphology, it was semi-globular, sharpened at the apical region where the radicle is located and oval toward the opposite end (Figure 1). The micropyle is located in the apical region at the end of the raphe. Average micropyle

Figure 1. Micropyle of Rubus geoides seed as seen with scanning electron microscopy (SEM) (a) and light microscopy (b).

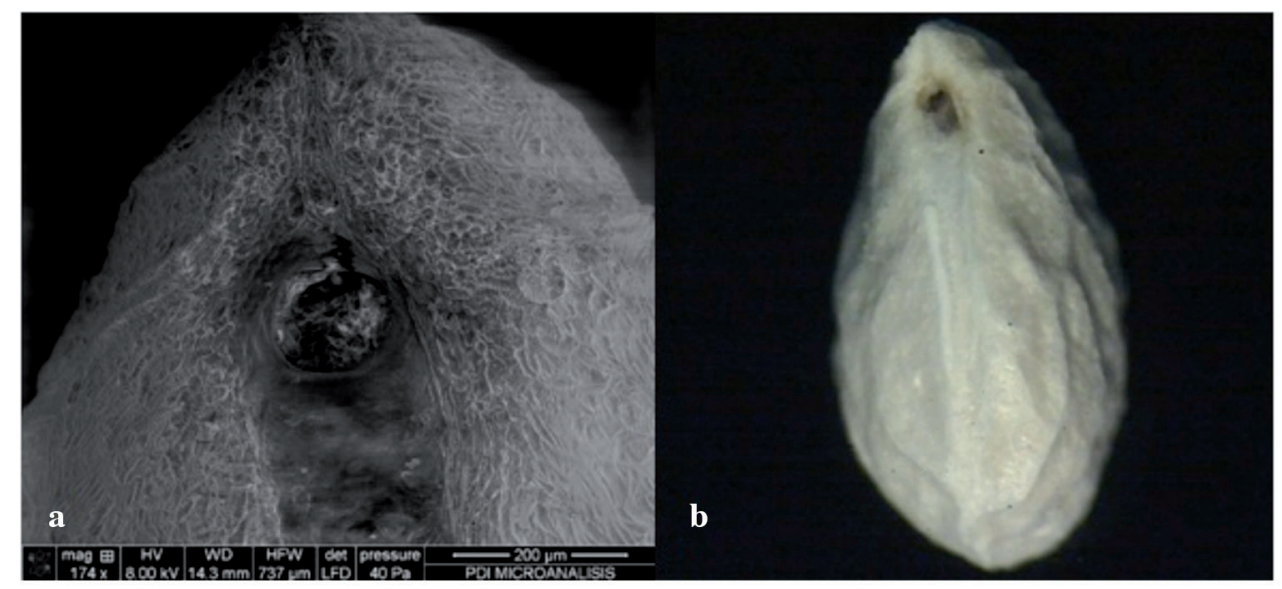


diameter was 125.5 microns (Figure 1). The raphe showed a straight to convex shape. In some seeds the raphe shape was very well defined, while in others, it was difficult to observe. Seed size was quite variable (Table 1) with averages that were within the range reported for other Rubus species (Hummer and Peacock, 1994; Wada and Reed, 2010).

Seed surface had an outstanding sculpturing (Figure 2) produced by small rounded or ocellated depressions and ridges throughout the whole seed surface. These ridges had very noticeable and pronounced edges on the upper part of the seed, becoming soft on their sides. The seed raphe is conspicuous and readily visible (Figure 1). Satomi and Naruhashi (1971) used the shape, surface sculpturing, and characteristic of the raphe as discriminating factors for species identification within the Japanese Rubus species. Based on our analyses, $R$. geoides seeds appeared morphologically similar to that of the cultivated raspberries (R. idaeus) (Figure 3 ) and the wild blackberry (R. ulmifolius), which however, are in other subgenus, Ideaobatus and Rubus, respectively.

As mentioned earlier, all Rubus species seeds are pyrenes, which anatomically consist, from outside inwards, of an endocarp, a seed coat, an endosperm, and the embryo (Tomlik-Wyremblewska et al., 2010). In $R$. geoides, the endocarp was hard and rough, and consists of several layers of sclerenchymatous lignified cells (Figures 4 and 5). Its thickness averaged $139 \mu \mathrm{m}(102-186 \mu \mathrm{m})$ and had three well defined zones: An outer zone that exhibits the surface described above, it was thin, with 2 to 3 -cell rows, where tracheids and vascular bundles were observed; a predominant and thicker middle zone, consisting of longitudinal regularly ordered lignified fibers closely packed together; and a less thick internal zone, with spherical regularly ordered lignified fibers (Figure 5). This description closely resembles the one described by Wada et al. (2011) for $R$. hoffmeisterianus Kunth \& C.D. Bouche, which also has a thin endocarp, and

Table 1. Average seed size and absolute size range of Rubus geoides $(\mathrm{n}=25)$, measured with scanning electron microscopy (SEM).

\begin{tabular}{lcc}
\hline Dimension & Average size & Size range \\
\hline Width, mm & 1.9 & $1.6-2.1$ \\
Thickness, mm & 1.3 & $1.1-1.8$ \\
Length, mm & 2.6 & $2.2-3.2$ \\
\hline
\end{tabular}

a middle and inner area composed of sclereids homogeneous in shape and size. The seed coat, located below the endocarp, presented few thin layers of cells that contain the embryo and endosperm (Figures 4 and 5). The size of the embryo, which depended on the size of the seed, varied between 1.6 to 2.0 $\mathrm{mm}$, and occupied most of the total seed volume, which was mainly filled by the cotyledons (Figures 4 and 5).

An elemental chemical analysis of the seed tissue made by Energy Dispersive X-Ray Spectrometry allowed for the separation of the endosperm cells, which exhibit a high $\mathrm{K}$ and $\mathrm{P}$ content (Figure 6).

\section{CONCLUSIONS}

Rubus geoides seed is semi-globular, pale brown, $2.6 \mathrm{~mm}$ in length, $1.9 \mathrm{~mm}$ in width and $1.3 \mathrm{~mm}$ in thickness. Seed surface is well sculptured, with a conspicuous raphe. The endocarp is hard, $139 \mu \mathrm{m}$ thick, and consists of several layers of sclerenchymatous lignified cells. This description

Figure 3. Rubus idaeus and $R$. geoides seed. Left: scanning electron microscopy (SEM) image. Right: SEM image showing seed endocarp surface.

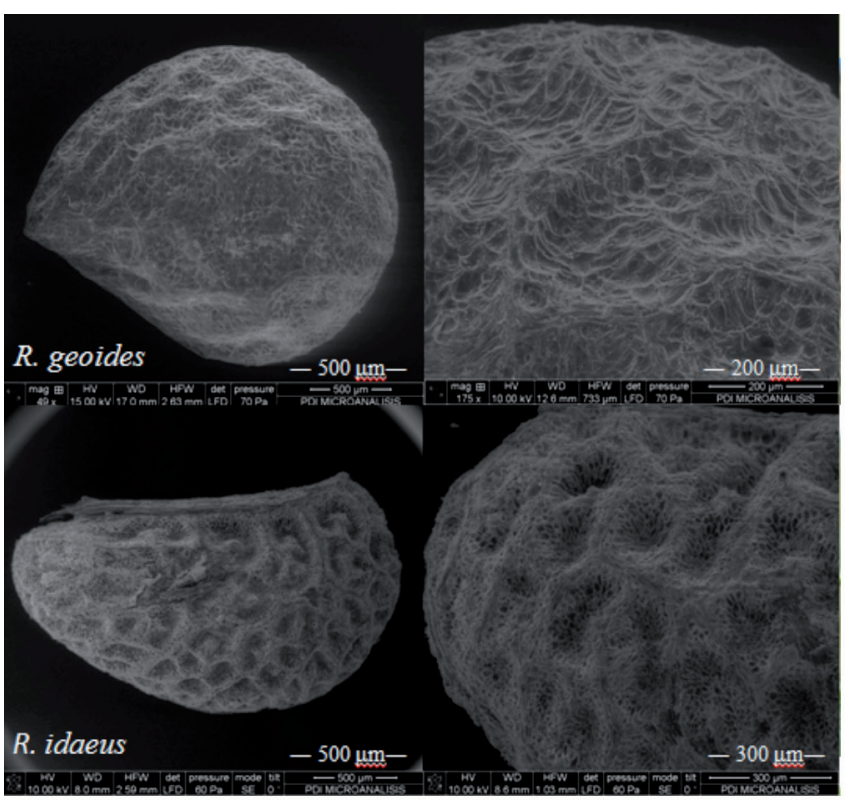

Figure 2. Rubus geoides seed: seed image using scanning electron microscopy (SEM) (a), seed endocarp surface using SEM (b), and seed image using light microscopy (c).

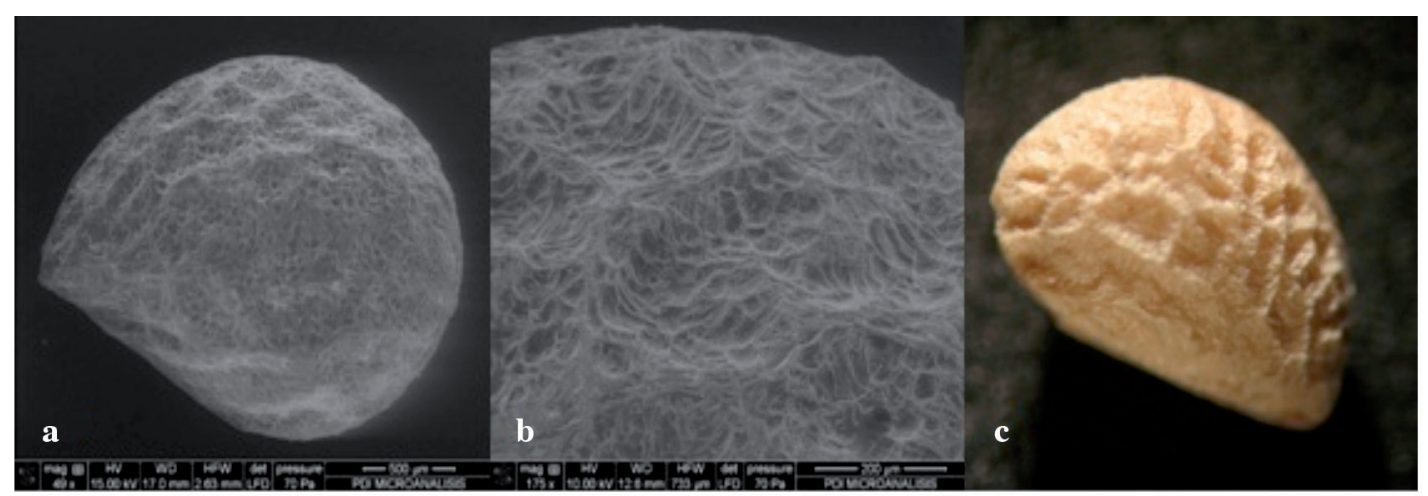


Figure 4. Scanning electron microscopy (SEM) images of Rubus geoides seed: seed slit (a) and seed cross section (b). Both images show the embryo and the seed coat.

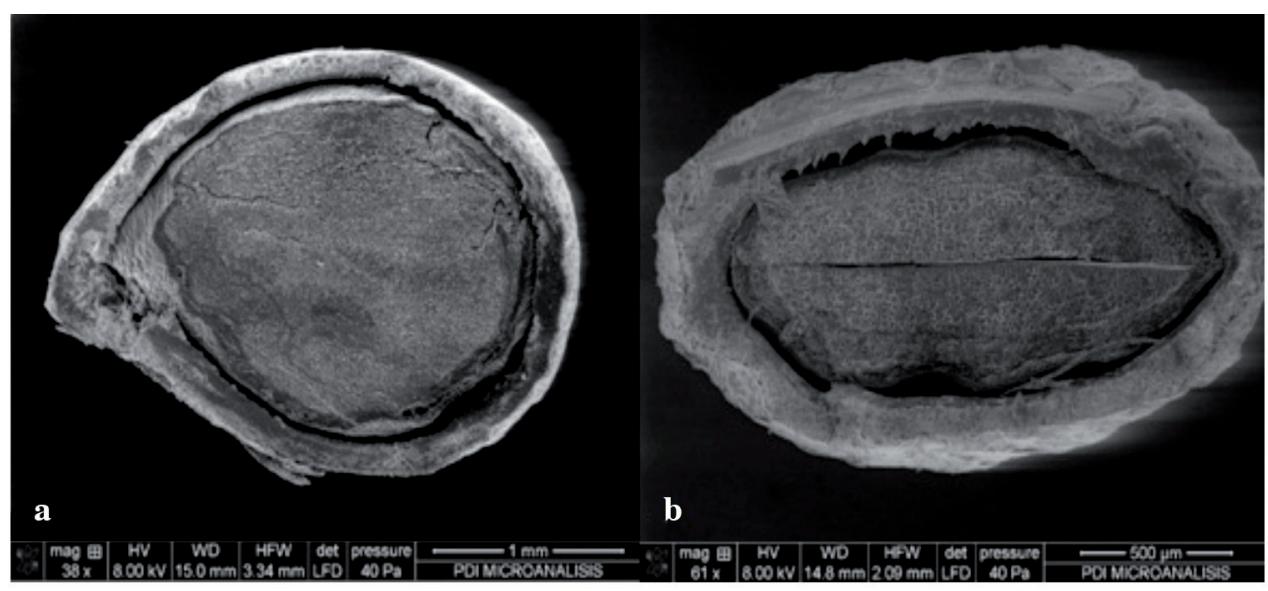

Figure 5. Scanning electron microscopy (SEM) image of Rubus geoides seed with three demarcated endocarp layers: external, middle, and inner.

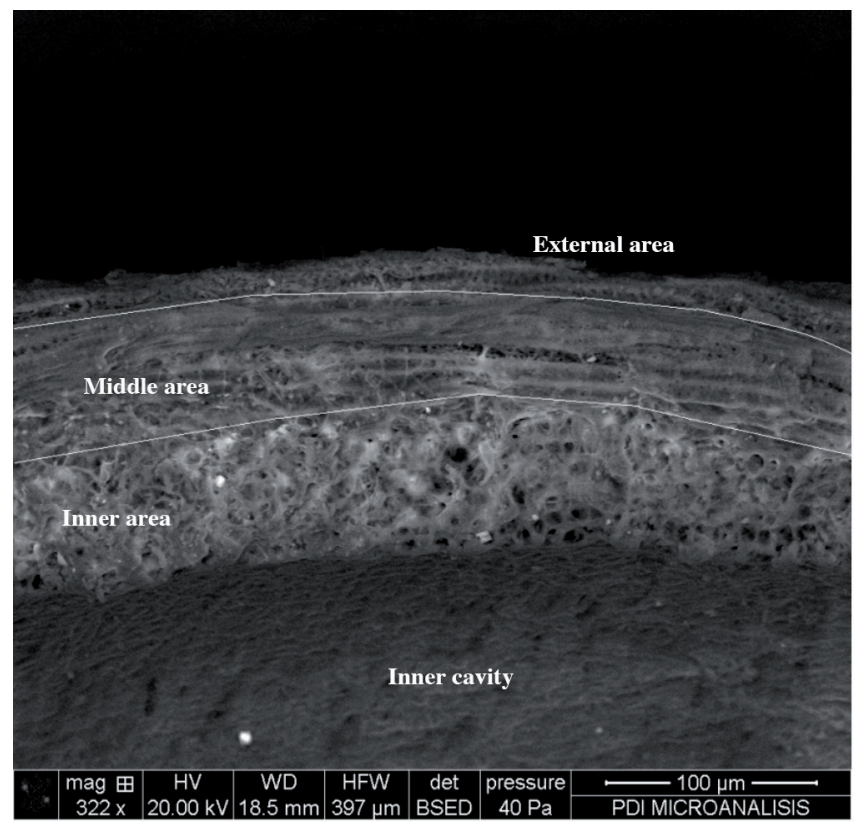

Figure 6. Elemental mapping of Rubus geoides seed in a cross section. Cotyledons, endosperm, seed coat and part of the endocarp are observed. Phosphorus and potassium are concentrated in the endosperm.

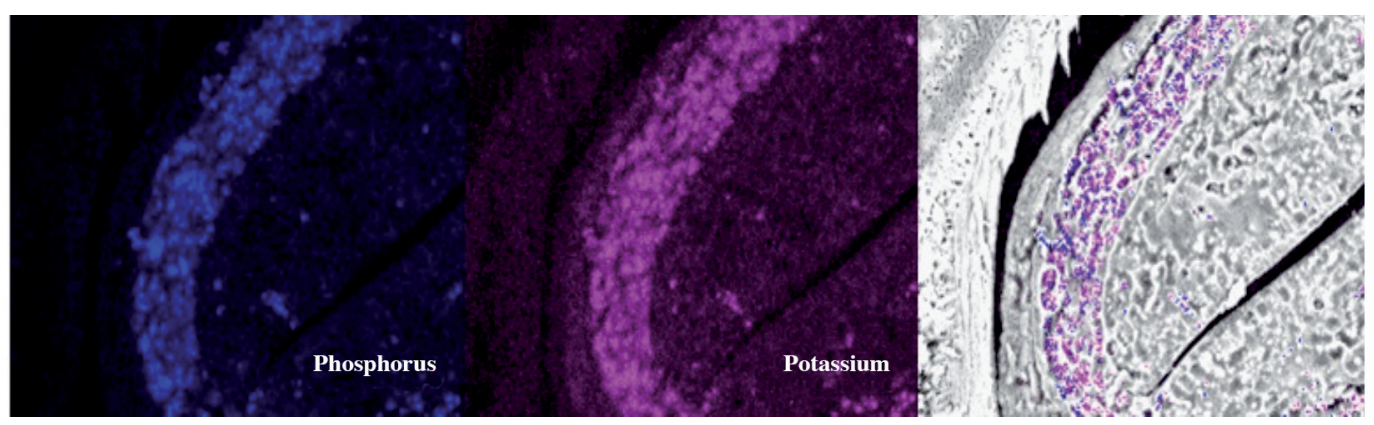


suggests that endocarp may be an impediment for seed germination as occurred in other Rubus species. Also, seed coat morphology may allow for the identification of the seed of this species.

\section{REFERENCES}

Arena, M.E., and G. Vater. 2005. Native and introduced species of small fruits in Austral Patagonia, Tierra del Fuego. p. 96-110. In R. Dris (ed.) Fruits: Growth, nutrition, and quality. WFL Publisher, Helsinki, Finland. http://www.isfae.org/book/php.

Bewley, J.D., K. Bradford, H. Hilhorst, and H. Nonogaki. 2013. Seeds, physiology and development, germination and dormancy. 391 p. Springer, New York, USA.

Cancino-Escalante, G.O., D. Barbosa, y C. Díaz. 2012. Diversidad genética de especies silvestres y cultivadas de Rubus L. de los municipios de Pamplona y Chitagá, región nororiental de Colombia. Bistua: Revista de la Facultad de Ciencias Biológicas 10(1):80-89.

Hummer, K.E, and D.N. Peacock. 1994. Seed dimension and weight of selected Rubus species. HortScience 29(9):1034-1036.

Jiménez-Aspee, F., C. Theoduloz, F. Ávila, S. Thomas-Valdés, C. Mardones, D. von Baer, et al. 2016. The Chilean wild raspberry (Rubus geoides $\mathrm{Sm}$.) increases intracellular GSH content and protects against $\mathrm{H}_{2} \mathrm{O}_{2}$ and methylglyoxal-induced damage in AGS cells. Food Chemistry 194:908-919. doi:10.1016/j. foodchem.2015.08.117.

Jiménez-García, S.N., R.G. Guevara-González, R. Miranda-López, A.A. Feregrino-Pérez, I. Torres-Pacheco, and M.A. VázquezCruz. 2013. Functional properties and quality characteristics of bioactive compounds in berries: Biochemistry, biotechnology, and genomics. Food Research International 54:1195-1207. doi:10.1016/j.foodres .2012.11.004.
Satomi, N., and N. Naruhashi. 1971. Seed of Japanese Rubus: I. Morphology. Kanazawa Daigaku Rigakubu Fuzoku Shokubutsuen Nenpo 4:1-17.

Thompson, M.M. 1995. Chromosome numbers of Rubus species at the National Clonal Germplasm Repository. Horticultural Science 30:1447-1452.

Tomlik-Wyremblewska, A., J. Zielinski, and M. Guzicka. 2010. Morphology and anatomy of blackberry pyrenes (Rubus L., Rosaceae). Elementary studies of the European representatives of the genus Rubus L. Flora 205:370-375. doi:10.1016/j. flora.2009.12.006.

Vauzour, D., K. Vafeiadou, C. Pendeiro, G. Corona, and J.P.E. Spencer. 2010. The inhibitory effects of berry-derived flavonoids against neurodegenerative processes. Journal of Berry Research 1:45-52. doi:10.3233/BR-2010-005.

Wada, B., and M. Reed. 2010. Seed coat morphology differentiates blackberry cultivars. Journal of American Pomology Society 64:151-160.

Wada, S., and M. Reed. 2011. Optimized scarification protocols improve germination of diverse Rubus germplasm. Scientia Horticulturae 130:660-664. doi:10.1016/j.scientia.2011.08.023.

Wada, S., J. Kennedy, and B. Reed. 2011. Seed-coat anatomy and proanthocyanidins contribute to the dormancy of Rubus seed. Scientia Horticulturae 130:762-768. doi:10.1016/j. scienta.2011.08.034.

Zasada, J., and J. Tappeiner. 2008. Rubus L. p. 984-996. In Bonner, F., and R. Karrfalt (eds.) The woody plant seed manual. Agriculture Handbook 727. USDA Forest Service, Washington, D.C., USA. 